\title{
Monitoring the coherence between ONS and PMI data - an update
}

Graeme Chamberlin, Valerie Fender and Zuhaib Khan

Office for National Statistics

\section{Summary}

In the last couple of years there has been strong interest in economic statistics as the UK economy recovers from its deepest post war recession. This article updates previous work examining the coherence between official economic data published by the Office for National Statistics and widely-used business survey data in the form of the Purchasing Managers Index to include this latest period.

\section{Introduction}

A number of business groups and trade associations provide indicators of UK economic activity. Although these are usually more qualitative and based on smaller samples than official data supplied by the Office for National Statistics (ONS), they are viewed by many as useful and timely statistics. Purchasing Managers Index (PMI) data are among the most prominent and widely used business surveys. For example, the Bank of England have stated that they place some emphasis on these surveys in forming their short-term view of the economy (see Ashley et al 2005 and Cunningham and Jeffery 2007).

Growing interest in this survey prompted ONS to investigate the coherence between PMI and National Accounts data, more specifically the monthly Index of Manufacturing and the monthly Index of Services. This analysis was first published in the appendix of Meader and Tily (2008) and a fuller description in Chamberlin (2008). A brief update of this work is now presented here.

PMI data is published by Markit Economics on behalf of the Chartered Institute of Purchasing and Supply (CIPS). Individual surveys for the manufacturing, construction and services sectors are published monthly. Although the indicators are very rapid, being published immediately after the reference quarter compared to 23-25 days for the Preliminary gross domestic product (GDP) estimate, there are trade-offs in terms of sample sizes and detail.

The PMI Report on Manufacturing is collected from a representative panel of around 600 companies. For the Report on Construction the PMI sample size is 170 companies in the UK construction sector. And for the Report on Services the PMI is collected from around 700 companies. Each of these sample sizes are substantially smaller than the monthly surveys 
administered by ONS for the Index of Manufacturing (Production) and the Index of Services. Furthermore, PMI surveys simply ask respondents to state whether output or activity has 'gone up', 'remained unchanged' or 'gone down' in the latest month. The results are presented as balance statistics between the proportion of firms reporting 'up' against 'down' and then normalised so that in aggregate: $50=$ no change, $0=$ unanimously down, and $100=$ unanimously up. Consequently, and unlike in official data collections, respondents cannot report an order of magnitude to output or activity changes over the month but only the direction.

As ONS and PMI data are reported on different bases a direct comparison is not straightforward. To achieve this two basic transformations are made to the PMI data:

- investigate correlation - ONS data is normally more strongly correlated with lags of PMI data. Whereas PMI data is a monthly indicator, headline ONS data for the Index of Manufacturing and Index of Services are reported as three-months-on-three-months growth rates, hence more past data is included in the measure. It might also be the case that PMI data, by the very nature of qualitative business survey collections, are influenced by forward looking factors such as business confidence regarding the economic outlook. Therefore, in making a comparison it is sensible to consider lags of PMI against ONS data

- standardise the units of measurement - ONS data is reported as a growth rate whereas PMI data as a balance statistic, so the measures are not directly comparable. There is a large literature on how balance statistics may be mapped to continuous growth rates which is summarised by Nardo (2003). However, here the PMI data is adjusted so that it has the same long-term average and standard deviation of the respective ONS data

A further consideration is the respective coverage of ONS and PMI measures. For the manufacturing sector both PMI and ONS data cover broadly the same activities, but for the services sector the coverage of PMI data is much narrower than in the official data. Therefore, like-for-like comparisons can only be made where differences in coverage have been accounted for.

\section{Manufacturing}

Figure 1 shows the comparison between the Index of Manufacturing and the adjusted PMI Report on Manufacturing (from January 1993 up to and including December 2010 ${ }^{1}$ ). A one month lag of the PMI data has the highest correlation with the ONS measure. Clearly, both data sources reflect the significant downturn in UK manufacturing output through 2008 and the majority of 2009.

Recovery in manufacturing growth towards the end of 2009 and early 2010 is also captured in both time series.

In general there is a strong coherence between ONS and PMI measures on manufacturing output with few large and sustained divergences. The main exception is in 1998-99 where there appears to be a genuine disagreement on the strength of the economy at the time. PMI balances in late 
1998 were close to where they were in 1991, but the official data shows only a modest slowdown in comparison to the fall in output during the early 1990s recession.

\section{Figure $1 \quad$ ONS and PMI indicators of manufacturing output}

Per cent, three-months-on-three-months

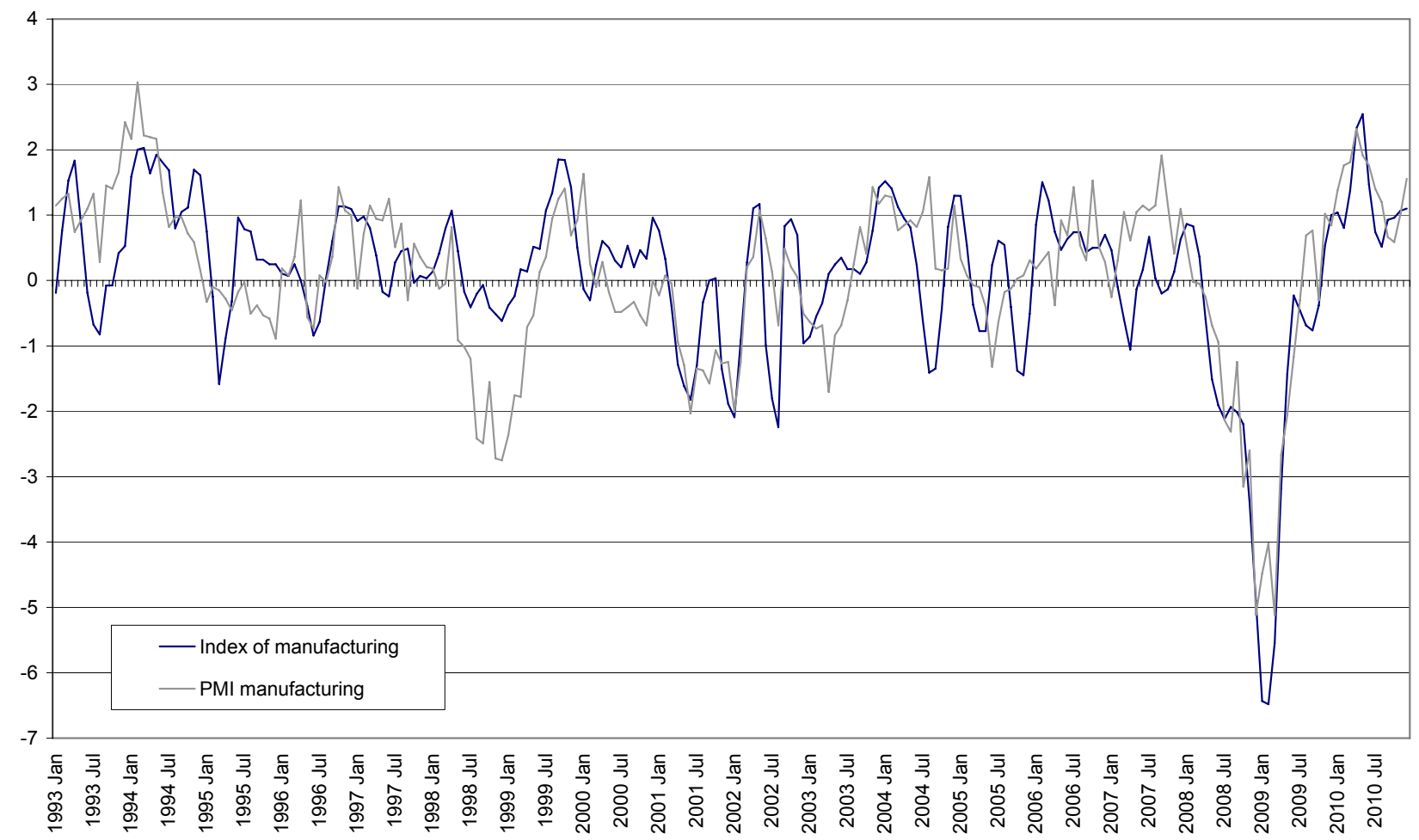

Source: ONS Index of Production and PMI Report on Manufacturing

\section{Services}

Comparing the ONS Index of Services with the PMI Report on Services is more complicated as the coverage between the two is different. Just under one half of the services sector (according to gross value added (GVA) weights making up the Index of Services) is not actually covered by the PMI, including:

- Wholesale and distribution (151 parts per 1000 in GVA weights)

- Letting of dwellings (90)

- Public administration and defence (69)

- Education (77)

- Health and social services (96)

- Sewage and refuse disposal (9)

- Private households with employed persons (6) 
Exclusion of these items from the PMI data may obviously lead to a divergence between the two data sources, especially if the above industries behave differently to the rest of the services sector. As a result, PMI data tends to be more heavily influenced by activity in business services and finance. Sections $\mathrm{J}$ and $\mathrm{K}$ in the Index of Services, which are financial intermediation and business services respectively, account for just under one third of total services gross value added. However, given what is excluded, its weight in the PMI survey would be approximately double that.

Figure 2 presents the three-months-on-three-months growth rates for:

- Index of Services adjusted to match PMI services coverage

- total Index of Services, and

- Index of Services of industries not included in PMI reports

\section{Figure 2 Index of Services (IoS) - various measures}

Per cent, three-months-on-three-months

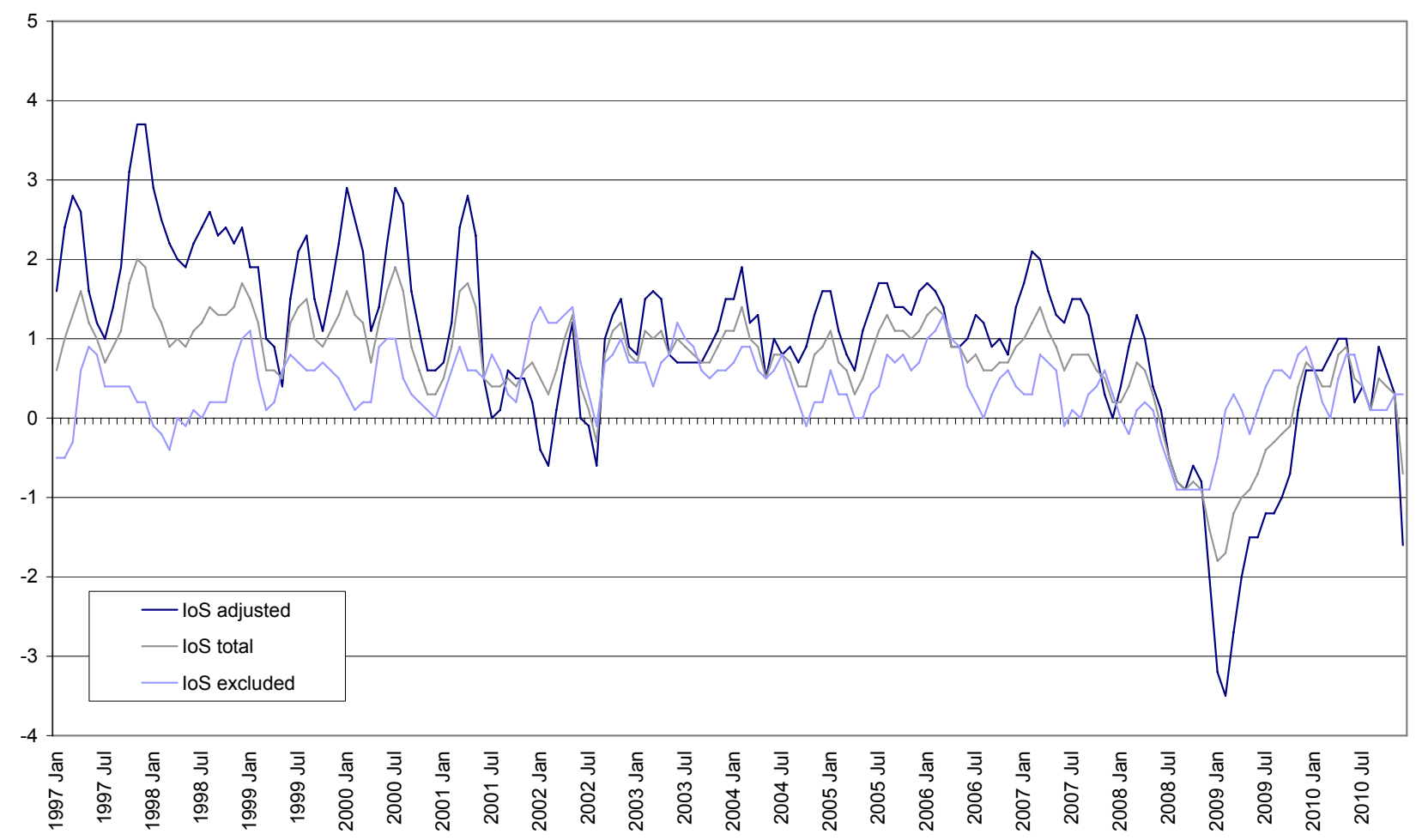

Source: ONS Index of Services

One of the key features in Figure 2 is the stronger contraction in the adjusted Index of Services than in the overall index. Considering the components that have been removed from the adjusted series this is not too surprising. Public administration and defence, education, health and social services, sewage and refuse disposal largely consist of public sector output, which tends to be relatively stable over the business cycle. Taken together these industries account for almost a third of total services output. 
Ownership of dwellings is also a relatively large and stable part of output accounting for around 10 per cent of gross valued added in services. This largely consists of the imputed rental activity of owner-occupiers who pay themselves to live in their own properties. As tenants of private and social landlords engage in market activity that is recorded in the National Accounts, failure to account for this otherwise non-recorded activity would make services output susceptible to shifts between the proportions of tenanted and owner-occupied households. It would also make international comparisons of the level of GDP difficult where these proportions differ across countries. The implicit output of this owner-occupier industry also tends to be relatively stable regardless of activity in the wider economy as the real consumption of housing services would not be expected to show large cyclical variation.

The adjusted series, as previously mentioned, is therefore driven to a larger extent by the remaining industries of which business services and finance are a large constituent part. One of the characteristic features of the most recent recession compared to those previously was the extent to which it was driven by a contraction in business-to-business demand. Transport and hotels and restaurants also contracted sharply in the recession, both of which will more significantly reflected in the adjusted than the total series.

Figure 3 presents a comparison of the adjusted Index of Services with the PMI Report on Services (up to December 2010).

\section{Figure 3 ONS and PMI indicators of services output}

Per cent, three-months-on-three-months

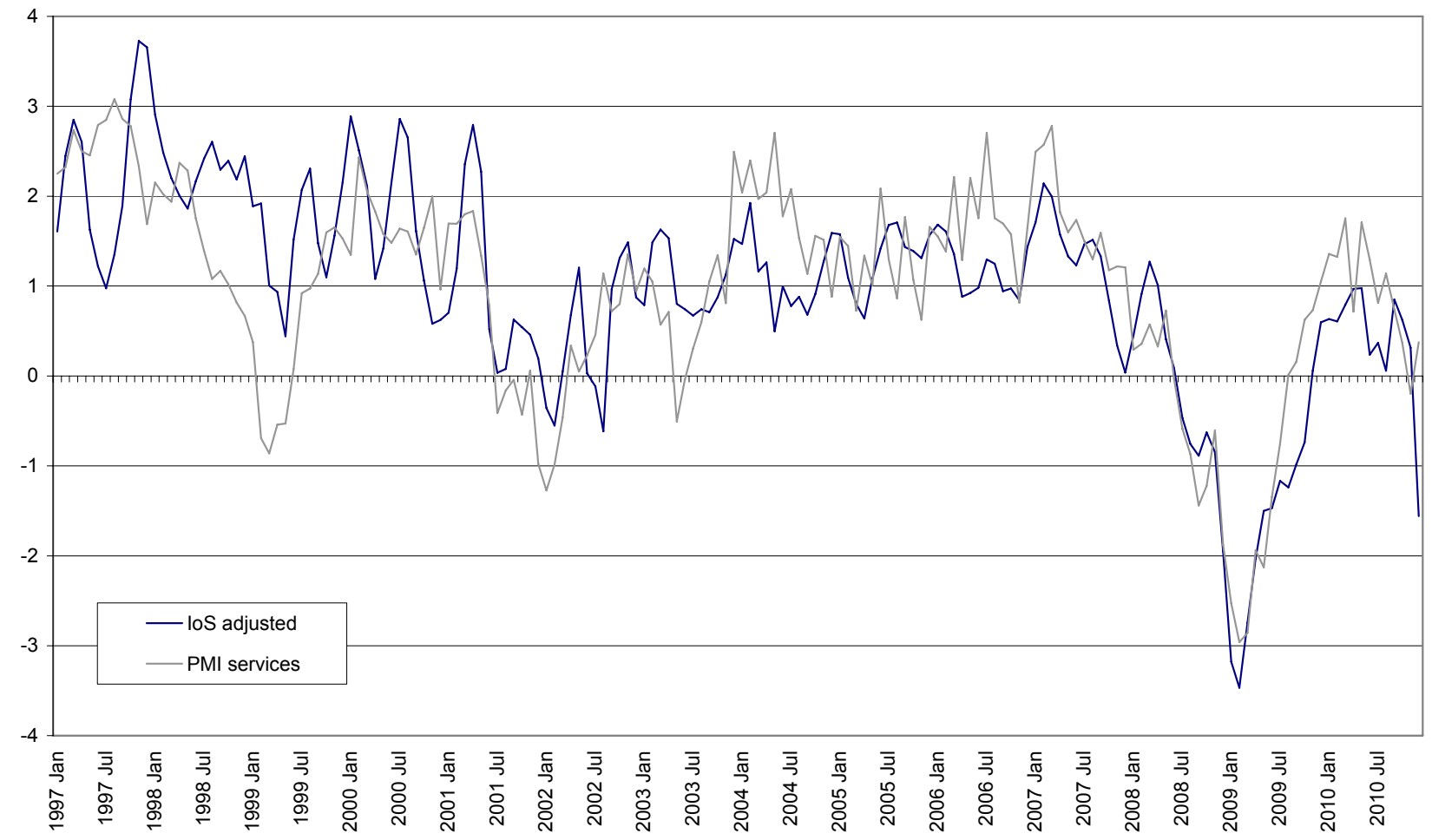

Source: ONS Index of Services and PMI Report on Services 
Here the PMI series has been:

- lagged by three months as this shows the strongest correlation with the Index of Services

- seasonally adjusted ${ }^{2}$ using the TRAMO-SEATS program (see Caporello and Maravall 2004), and

- standardised so it shares the same mean and standard deviation as the adjusted Index of Services

Once again, the two time series generally show a good degree of coherence, especially through the recession period 2008-2009. However, there are some periods of notable differences:

- as in the case of manufacturing output there is a disagreement between the strength of services activity in 1998-99. Whilst PMI data show a contraction, ONS data are more robust during this period

- PMI data reports stronger activity in 2004

- the speed and strength of the recovery in services output in the second half of 2009 was faster in the PMI report than the Index of Services. The PMI reported its first positive balance in April 2009 whilst the first positive growth rate in the Index of Services (based on a three-months-onthree-months period) was reported in November 2009

- the disruption caused by the bad weather in December 2010 is more evident in the ONS data. The December PMI (not seasonally adjusted) was 49. In the three months to December 2010 the adjusted Index of Services was 1.6 per cent lower than in the previous three month period

\section{GDP*}

Gross Domestic Product star (GDP*) is described by Butler (2005) as a measure of (private sector) output consistent with the industries covered in PMls for manufacturing, services and construction. $\mathrm{GDP}^{*}$ can be constructed using the Index of Manufacturing (Figure 1), the adjusted Index of Services (Figures 2 and 3), and a monthly construction series that is interpolated (using a cubic spline) from the published quarterly data. These component parts can then be weighted together using official GVA weights.

Figure 4 shows how GDP* corresponds to an aggregated PMI index which has been lagged one month (based on the strongest correlation coefficient) and standardised to the mean and standard deviation of the GDP* time series. This again shows two broadly consistent time series, although the periods of differences noted for services activity are also relevant here.

Despite attempts to reconcile the two data sources it is not alarming that some differences still remain - a reflection that the two data sources are methodologically different. One key issue, which might explain why PMI data sometimes differ from official estimates, is that survey respondents can only report on the direction of output or activity changes and not the size. As a result, a broad consensus that output/activity is moving in a certain direction may generate fairly strong survey balances even if those movements are in themselves fairly modest. 


\section{Figure $4 \quad$ GDP* and an aggregate PMI}

Per cent, three-months-on-three-months

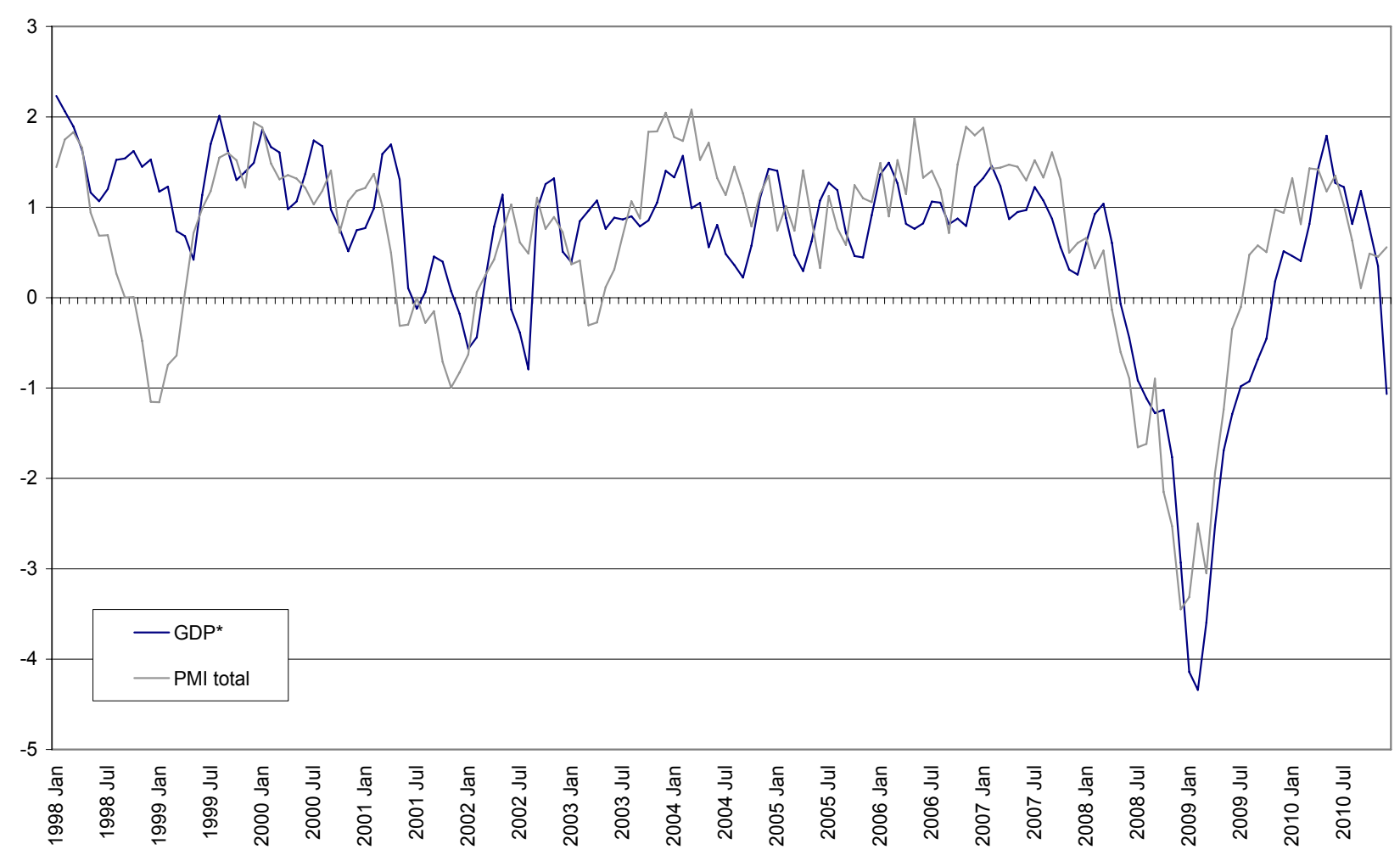

Source: ONS and PMI surveys

The differences in 1998 and 1999 may be a case in point. At this time, the Asian financial crisis, the near collapse of Long Term Capital Management following the sovereign default in Russia and its contagion to Latin America and a slowdown in global growth pointed to weaker activity in the UK. Preliminary estimates of GDP were much weaker than revised estimates, and more in tune with the PMI data. However, it has since emerged that consumer spending during this period was more resilient than early estimates have suggested, in fact growing above its longer term average through 1996-99. This may have been aided by a loosening in monetary policy as interest rates fell from 7.25 per cent in October 2008 to 5.0 per cent in June 1999 (a total of 225 basis points), including three monthly reductions of 50 basis points each. Consumption was also boosted by a significant improvement in the terms of trade through falling goods prices after China turned outwards in the early part of the decade.

Therefore, it is possible that where survey responses can only indicate a direction of change reported swings in activity reflect the degree of consensus about the change as much as the magnitude of that change. This episode also urges caution when attempting to use differences between PMI and early ONS estimates to predict subsequent revisions to the latter. Here, subsequent revisions to GDP data actually moved ONS and PMI indicators further apart.

The same logic may apply to the apparent faster recovery in PMI balances than ONS growth figures during the second half of 2009. Once it became accepted that the economic condition was starting to improve, or at the very least was not as bad as previously, then the pick up in survey 
balances may be sharper than in actual output itself - especially if those output increases were rather tentative.

\section{Conclusions}

This article uses a simple approach to analyse the coherence between ONS and PMI data on economic activity in the manufacturing, services and overall sectors of the UK economy. As the analysis has been carried on monthly data it not surprising that there is some short-term volatility in each time series, but over a longer time period the results show the two data sources to generally exhibit similar patterns of economic activity. There are, however, some periods where there are clear differences between the two measures, specifically the extent of the slowdown in 1998-99 and the speed of the recovery in 2009.

PMI data have been mapped onto the respective ONS data by adjusting their means and standard deviations to fit that on the ONS data. This naturally assumes that the underlying distributions of the two data sources are the same (that is average growth rates and the variance of these are equal) which may not be a too stronger assumption given that both statistics are aiming to capture the same underlying activity. However, it also assumes that these distributions are best represented by a normal distribution, and further investigation along the lines proposed by Mitchell (2002) may offer scope for improving the coherence analysis.

\section{Notes}

1. PMI data for the manufacturing sector starts in 1990. Because the data around the time of the early 1990s recession is quite volatile, and this is towards the beginning of the sample, the coherence analysis is chosen to start in 1993.

2. A seasonally adjusted version of the PMI services activity balance is published but only goes back to 2003. Therefore it is decided to seasonally adjust the non-adjusted series in order to provide a longer back series to 1996.

\section{Contact}

elmr@ons.gov.uk

\section{References}

Ashley J, Driver R, Hayes S and Jeffrey C (2005) 'Dealing with data uncertainty', Bank of England Quarterly Bulletin, Spring 2005

Butler J (2005) ‘GDP doubts. What evidence?', HSBC Global Research 
Caporello G and Maravall A (2004) 'Program TSW: Revised reference manual', Banca de Espana

Chamberlin G (2008) 'Monitoring the coherence of ONS and Purchasing Managers Index data', Economic \& Labour Market Review, 2(5), pp 23-28

Cunningham A and Jeffrey C (2007) 'Extracting a better signal from uncertain data', Bank of England Quarterly Bulletin, Autumn 2007

Meader R and Tily G (2008) 'Monitoring the quality of the National Accounts' Economic \& Labour Market Review, 2(3), pp 24-33

Mitchell J (2002) 'The use of non-normal distributions in quantifying qualitative survey data', Economic Letters, 76, pp 101-107

Nardo M (2003) ' Quantification of qualitative survey data: a critical assessment' Journal of Economic Surveys, 17(5), pp 645-68 